\title{
Butter and butter oil classification by PTR-MS
}

\author{
S. M. van Ruth · A. Koot - W. Akkermans · \\ N. Araghipour $\cdot$ M. Rozijn $\cdot$ M. Baltussen . \\ A. Wisthaler · T. D. Märk · R. Frankhuizen
}

Received: 5 May 2007/Revised: 26 June 2007/Accepted: 9 July 2007 / Published online: 2 September 2007

(C) Springer-Verlag 2007

\begin{abstract}
The potential of proton transfer reaction mass spectrometry (PTR-MS) as a tool for classification of milk fats was evaluated in relation to quality and authentication issues. Butters and butter oils were subjected to heat and off-flavouring treatments in order to create sensorially defective samples. The effect of the treatments was evaluated by means of PTR-MS analysis, sensory analysis and classical chemical analysis. Subsequently, partial least square-discriminant analysis models (PLS-DA) were fitted to predict the matrix (butter/butter oil) and the sensory grades of the samples from their PTR-MS data. Using a 10fold cross-validation scheme, $84 \%$ of the samples were successfully classified into butter and butter oil classes. Regarding sensory quality, $89 \%$ of the samples were correctly classified. As the milk fats were fairly successfully classified by the combination of PTR-MS and PLS-DA, this combination seems a promising approach with potential applications in quality control and control of regulations.
\end{abstract}

Keywords Butter - Butter oil - Headspace analysis . Matrix $\cdot$ Sensory analysis $\cdot$ Volatile compounds

S. M. van Ruth $(\bowtie) \cdot$ A. Koot · M. Rozijn ·

M. Baltussen · R. Frankhuizen

RIKILT, Institute of Food Safety, P.O. Box 230, Wageningen

UR, 6700 AE Wageningen, The Netherlands

e-mail: saskia.vanruth@wur.nl

W. Akkermans

Biometris, P.O. Box 16, Wageningen UR,

6700 AA Wageningen, The Netherlands

N. Araghipour · A. Wisthaler · T. D. Märk

Institute of Ion Physics and Applied Physics,

Leopold-Franzens University, Technikerstr. 25,

6020 Innsbruck, Austria

\section{Introduction}

Butter is a water-in-oil emulsion and essentially the fat of the milk. It is usually made from sweet cream and it is salted. However, it can also be made from acidulated or bacteriologically soured cream, and saltless butters are also available. The principal constituents of normal salted butter are fat $(80-82 \%)$, water $(15.6-17.6 \%)$, salt (ca. $1.2 \%$ ) as well as protein, calcium and phosphorus (ca. $1.2 \%)$. Butter also contains fat-soluble vitamins A, D and E. Butter oil, anhydrous milk fat, can be manufactured from either butter or from cream. For the manufacture from butter, non-salted butter from sweet cream is normally used. Melted butter is passed through a centrifuge, to concentrate the fat to $99.5 \%$ or greater. This oil is heated again to $90-95{ }^{\circ} \mathrm{C}$ and vacuum cooled before packaging. Milk fat is a complicated mixture of triglycerides that contain numerous fatty acids of varying carbon chain lengths and degrees of saturation. The proportions of the various fatty acids present will also vary depending on the conditions surrounding the production of milk. Milk fats can be separated into various fractions on the basis of their melting points. The technique consists of melting the entire quantity of fat and then cooling it down to a predetermined temperature. The triglycerides with the higher melting point will then crystallize and settle out (http://www.foodsci.uoguelph.ca/dairyedu/ butter.html).

The acceptance of a food strongly depends on the impressions of its flavour. A constantly increasing number of consumers attach greater importance to the quality of foodstuffs in their diet, rather than to quantity. In view of the wide variety of products marketed, the consumer should be given clear information regarding product origin and specific product quality characteristics. An authentic 
food is one, which conforms to the description that is provided by the producer. The description may relate to the process history of a product, its geographic origin or the species or variety of ingredients [1]. Product labelling is one of the issues that helps the consumer and the authorities to undertake legal action, because an infringement of the label could result in a charge in the court of justice.

Usually, the driving force behind adulteration is revenue maximization, obtained either by using a low cost ingredient to (partially) substitute a more expensive one or by (partially) removal of the valued component in the hope that the adulterated product will be neither perceived nor detected by the authorities and the consumer [2]. Traditional analytical strategies to guarantee quality and to uncover adulteration have relied on determination of the amount of marker compound(s) in a suspect material and a subsequent comparison of the value(s) obtained with those established for equivalent material of known provenance [1].

The increasing consumer awareness of food safety and authenticity issues has led to the development and application of new and sophisticated techniques. Specific techniques used for authentication purposes are spectroscopic techniques, isotopic analysis, chromatography, volatile analysis, polymerase chain reaction, enzymelinked assay and thermal analysis [3]. Certain methods, such as near infrared spectroscopy and certain volatile analysis techniques are based on the generation of a "fingerprint" of foods. Normal variations in food composition due to environmental and processing effects are accommodated by collecting fingerprints of a large number of samples of a particular food. These are then used in a classification procedure to segregate authentic from adulterated ingredients or products [1].

Proton transfer reaction mass spectrometry (PTR-MS) is a promising technique for analysis of volatile compounds and has been used to investigate different issues in food science [4-6], including correlation with sensory data [79]. Proton transfer reactions are used to induce chemical ionization of the vapours to be analysed. The sample gas is continuously introduced into a drift tube, where it is mixed with $\mathrm{H}_{3} \mathrm{O}^{+}$ions formed in a hollow cathode ion source. Volatile compounds that have proton affinities higher than water $(>166.5 \mathrm{kcal} / \mathrm{mol})$ are ionized by proton transfer from $\mathrm{H}_{3} \mathrm{O}^{+}$, mass analysed in a quadrupole mass spectrometer and eventually detected as ion counts/s (cps) by a secondary electron multiplier [10]. The outcome is a mass resolved fingerprint of the total volatile profile of a sample. PTR-MS is interesting for this fingerprinting approach as (1) it requires no pre-treatment of the sample, (2) it allows rapid measurements (typically $<1 \mathrm{~min}$ for a complete mass spectrum) and (3) the technique is extremely sensitive (ppt level).
The aim of the present study was to evaluate PTR-MS for classification of milk fat samples in relation to quality and authentication issues. Butters and butter oils were subjected to two different heat treatments and an off-flavouring treatment in order to create sensorially defective samples. The effect of the treatments was evaluated by classical methods, PTR-MS analysis and sensory analysis. Subsequently, statistical models were fitted to predict the matrix and the sensory grades of the samples from their PTR-MS data.

\section{Materials and methods}

\section{Materials}

Seven types of commercial butters and nine types of commercial butter oils (i.e. 16 milk fat samples) were kindly provided by VIV Vreeland (Zelhem, The Netherlands). Table 1 and 2 specify the various samples. The types were selected to cover a wide range of sample material. They were produced from cow's milk, except for one type, which was goat butter from goat's milk. The sample types originated from Europe, Canada and New Zealand. Some were mixtures of origins. The various butter oils comprised two fractionated UK butter oils, a stearin and olein fraction, as well as one deodorized butter oil. The butter oils from Canada and New Zealand had been produced from the butter batch of the same origin.

After dividing the types of butter in sample portions, four experimental conditions were created: untreated, heat treatment 1 , heat treatment 2 , and off-flavouring treatment. The untreated samples of all types of butter and butter oil were analysed. The samples were randomly assigned to the treatments, not all samples were subjected to each treatment. The various treatments are specified for each sample in Table 1 and 2.

For the two heat treatments and the off-flavouring procedure, aliquots of $250 \mathrm{~g}$ of butter or butter oil were spread out in a layer (thickness $1.75 \pm 0.25 \mathrm{~cm}$, surface area $275 \pm 25 \mathrm{~cm}^{2}$ ) on a porcelain plate. Ten samples underwent heat treatment 1 : they were placed at $30{ }^{\circ} \mathrm{C}$ for $16 \mathrm{~h}$ and subsequently stored at $50^{\circ} \mathrm{C}$ for 3 hours, in absence of light. Heat treatment 2 involved six samples, which were stored in an oven at $24{ }^{\circ} \mathrm{C}$ for 14 days in the absence of light. Five samples were off-flavoured with ethyl butyrate. The porcelain plate with the sample material was placed in a desiccator at room temperature for 7 days in the absence of light. In the desiccator, a beaker containing $100 \mathrm{ml}$ of ethyl butyrate (Merck 800500, Darmstadt, Germany; $1 \mathrm{ml}$ ethyl butyrate/l water) was placed. 
Table 1 Peroxide values, free fatty acid concentrations and sensory quality grades of treated and untreated butter samples of different origins
+ is good quality butter, - is poor quality butter

\begin{tabular}{|c|c|c|c|c|}
\hline \multirow[t]{2}{*}{ Sample } & \multirow{2}{*}{$\begin{array}{l}\text { Peroxide } \\
\text { value } \\
(\mathrm{mEq} / \mathrm{kg})\end{array}$} & \multirow{2}{*}{$\begin{array}{l}\text { Free fatty acid } \\
\text { concentration } \\
(\% \mathrm{w} / \mathrm{w})\end{array}$} & \multicolumn{2}{|c|}{ Sensory quality } \\
\hline & & & Score & Comments \\
\hline \multicolumn{5}{|l|}{ Untreated } \\
\hline Canada & 0.050 & 0.308 & + & \\
\hline Ireland & 0.081 & 0.283 & - & Gone off, acidic \\
\hline NL1 & 0.071 & 0.162 & + & \\
\hline NL2 & 0.200 & 0.166 & + & \\
\hline NL goat butter & 0.038 & 0.079 & - & Yeast \\
\hline New Zealand & 0.099 & 0.127 & + & \\
\hline Portugal & 0.039 & 0.142 & + & \\
\hline \multicolumn{5}{|l|}{ Heat treatment 1} \\
\hline NL1 & 0.129 & 0.158 & + & \\
\hline NL2 & 0.199 & 0.126 & - & Salty \\
\hline New Zealand & 0.269 & 0.130 & + & \\
\hline Portugal & 0.040 & 0.134 & - & Cheesy, $\mathrm{H}_{2} \mathrm{~S}$, rancid \\
\hline \multicolumn{5}{|l|}{ Heat treatment 2} \\
\hline Canada & 0.251 & 0.304 & + & \\
\hline NL1 & 0.240 & 0.170 & + & \\
\hline Portugal & 0.120 & 0.771 & - & Cheesy, packaging material \\
\hline \multicolumn{5}{|c|}{ Off-flavour treatment } \\
\hline NL goat butter & 0.121 & 0.130 & - & Cheesy, soapy, strong, ethyl butyrate flavour \\
\hline Repeatability & 0.011 & 0.009 & & \\
\hline
\end{tabular}

\section{Peroxide value}

The pre-treatment of the samples consisted in melting $18 \mathrm{~g}$ of butter (oil) in a stove at $50{ }^{\circ} \mathrm{C}$, followed by filtration over a water-separating filter. The peroxide value (POV) of each sample was determined according to international standard IDF 74A:1991. Calibration curves of $\mathrm{Fe}(\mathrm{III})$ chloride were used to determine the peroxide concentrations in the samples and ranged from 5 to $20 \mu \mathrm{g} \mathrm{Fe}^{3+}$ to $1-15 \mathrm{Fe}^{3+}$. Two replicates of each sample were analysed.

\section{Free fatty acids}

The pre-treatment of the samples consisted in melting $18 \mathrm{~g}$ of butter (oil) in a stove at $50{ }^{\circ} \mathrm{C}$, followed by filtration over a water-separating filter. The FFA value of each sample was determined according to international standard IDF 6B:1989.

\section{PTR-MS analysis}

For headspace analysis, $5 \mathrm{~g}$ of butter (oil) was placed in a glass flask $(100 \mathrm{ml})$ at $20{ }^{\circ} \mathrm{C}$ for $45 \mathrm{~min}$ to allow equilibration. Two replicates of each sample were analysed. The headspace of the samples was analysed at $20{ }^{\circ} \mathrm{C}$ by PTRMS, according to the method described by Lindinger et al. [11]. A constant drift voltage of $600 \mathrm{~V}$ and a pressure of $2.1 \pm 0.1$ mbar were maintained in the reaction chamber. The headspace was drawn from the sample flask at a rate of $50 \mathrm{ml} / \mathrm{min}, 32 \mathrm{ml} / \mathrm{min}$ of which was led through a heated transfer line into the high sensitivity PTR-MS for on-line analysis. Data were collected for the mass range $\mathrm{m} / \mathrm{z} 20$ 150 using a dwell time of 0.5 s.mass $^{-1}$. The instrument was operated at a standard $\mathrm{E} / \mathrm{N}$ (ratio of electric field strength across the drift tube, E, to buffer gas density, N) of $138 \mathrm{Td}\left(1 \mathrm{Td}=10^{-17} \mathrm{~cm}^{2} \mathrm{~V}\right.$ molecule $\left.{ }^{-1}\right)$. Inlet and drift chamber temperatures were $60^{\circ} \mathrm{C}$. Each sample was analysed for at least 5 full mass scans. The headspace concentrations of the compounds during the cycles \#2, \#3 and \#4 were calculated as described by Hansel et al. [12] and background and mass discrimination corrections were applied. Headspace concentrations were subsequently averaged over the three mass scans for further statistical analysis. Preliminary experiments were carried out in which some of the butter and butter oil samples were analysed for seven cycles. The data did not show consistent changes in headspace concentrations (especially no decrease) after the first cycle. Therefore, cycles \#2, \#3 and \#4 were selected for calculations. Equilibrium conditions were unlikely to exist during the measurements, because of 
Table 2 Peroxide values, free fatty acid concentrations and sensory quality grades of treated and untreated butter oil samples of different origins

+ is good quality butter oil, - is poor quality butter oil

\begin{tabular}{|c|c|c|c|c|}
\hline \multirow[t]{2}{*}{ Sample } & \multirow{2}{*}{$\begin{array}{l}\text { Peroxide } \\
\text { value } \\
(\mathrm{mEq} / \mathrm{kg})\end{array}$} & \multirow{2}{*}{$\begin{array}{l}\text { Free fatty acid } \\
\text { concentration } \\
(\% \mathrm{w} / \mathrm{w})\end{array}$} & \multicolumn{2}{|c|}{ Sensory quality } \\
\hline & & & Score & Comments \\
\hline \multicolumn{5}{|l|}{ Untreated } \\
\hline Canada & 0.075 & 0.264 & + & \\
\hline Denmark & 0.066 & 0.114 & + & \\
\hline New Zealand & 0.100 & 0.123 & + & \\
\hline Poland & 0.323 & 0.213 & + & \\
\hline UK & 0.086 & 0.257 & + & \\
\hline UK stearin fraction & 0.051 & 0.198 & + & \\
\hline UK olein fraction & 0.086 & 0.285 & + & \\
\hline Deodorized mix & 0.022 & 0.070 & + & \\
\hline Mixture of origins & 0.070 & 0.135 & + & \\
\hline \multicolumn{5}{|l|}{ Heat treatment 1} \\
\hline Canada & 0.134 & 0.262 & + & \\
\hline Denmark & 0.139 & 0.106 & + & \\
\hline New Zealand & 0.317 & 0.114 & + & \\
\hline Poland & 0.327 & 0.210 & + & \\
\hline UK & 0.149 & 0.254 & + & \\
\hline Deodorized mix & 0.105 & 0.068 & + & \\
\hline \multicolumn{5}{|l|}{ Heat treatment 2} \\
\hline Canada & 0.174 & 0.268 & + & \\
\hline Denmark & 0.224 & 0.114 & + & \\
\hline Deodorized mix & 0.124 & 0.072 & + & \\
\hline \multicolumn{5}{|l|}{ Off-flavour treatment } \\
\hline New Zealand & 0.348 & 0.129 & - & Off-flavour: strong, ethyl butyrate flavour \\
\hline Poland & 0.326 & 0.214 & - & Off-flavour: strong, ethyl butyrate flavour \\
\hline UK & 0.128 & 0.272 & - & Off-flavour: strong, ethyl butyrate flavour \\
\hline Mixture of origins & 0.212 & 0.138 & - & Off-flavour: ethyl butyrate flavour, rancid, strong \\
\hline Repeatability & 0.012 & 0.010 & & \\
\hline
\end{tabular}

flow rates and glassware dimensions. However, no effect of resistance to mass transfer of the volatiles from butter (oil) into the headspace was observed. This may be due to the relative low concentrations present in the headspace. The effect of mass transfer over the product/air interface is expected especially for volatile compounds with high air/ product partition coefficients. As butter (oil) has a fairly hydrophobic nature, and most volatile compounds are hydrophobic as well, the headspace concentrations were relatively low as expected.

\section{Sensory analysis}

The 37 butter and butter oil samples were examined for their odour/flavour properties by a professional sensory laboratory that specializes in butter (oil) evaluations for control of EU regulations (COKZ, Leusden, The Netherlands). The samples were assessed and graded for their odour and flavour qualities by three assessors at $18{ }^{\circ} \mathrm{C}$. Good quality samples had to meet the criterion "good quality and specific for the particular product". Reference samples of good quality material were provided before the evaluation of the samples. If samples did not comply, defects were described according to defects listed in $E U$ regulation 213/2001, Annex VII, Tables 1 and 2. Samples were considered of poor sensory quality if at least two out of the three assessors detected defects.

\section{Statistical analysis}

The data of pairs of replicate PTR-MS analyses were subjected to principal component analysis (PCA) followed by Varimax rotation in order to investigate relationships between samples and masses. Spectral PTR-MS data were also subjected to analysis of variance (ANOVA) to determine significant differences between samples. 
The log transformed headspace concentrations measured by PTR-MS were subjected to partial least square-discriminant analysis (PLS-DA) in order to estimate classification models for the milk fat samples. These models predicted either the matrix or the sensory quality by the PTR-MS data, PLS-Toolbox, Matlab routines [13]. PLS-DA performs a principal component analysis-like reduction on the predictor variables. The dimensions extracted are composed such that they exhibit maximum correlation with Y (class membership, e.g. good versus poor sensory quality). After estimation of the classification model, the performance of the fitted model was evaluated by cross-validation. A leave-10\%-out procedure was followed. Of the samples, $10 \%$ were randomly removed from the data set, and a model, built with the remaining samples was used to classify these left out samples. The procedure was repeated ten times to allow the use of all samples. The number of components that is extracted is an important parameter in a PLS model. Models were fitted for 1, 2 and 3 components (dimensions), each time, followed by the cross validation described above. The most appropriate number of components was selected.

Two methods were employed to assess the "confidence" that can be attached to the solution found. First, two random permutations of the class labels were performed, after which the entire classification was repeated. Classification results obtained with these distorted data are expected to be less accurate than the results obtained with the original data. If not, the model might fit merely noise. Next, the random cross validation was repeated a large number of times (100), which gave insight into the repeatability of the randomly generated cross validation results. This procedure was carried out both for the original data and with permuted data. For the permuted data, a new permutation was generated in each of the 100 replications. The results were summarized as follows. One of the PLS-DA outputs is a posterior probability $p=$ $\left(p_{1} p_{2} \ldots p_{k}\right)$ for membership in each of the $k$ classes. The probabilities are for membership in this class versus membership not in this class, so that the $C$ probabilities in $p$ do not have to sum up to 1 . The sample is assigned to the class with the highest posterior probability. Let $p_{m}$ be the probability for this class, and let $p_{m 2}$ be the probability for the class with the second-largest posterior probability. Then

$C=\frac{p_{t}}{p_{m}+p_{m 2}}$

(where $p_{t}=p_{m}$ when the classification is correct, and $p_{t}=$ $p_{m 2}$ when the classification is incorrect) is a quantity with values between 0 and 0.5 for an incorrect classification, and between 0.5 and 1 for a correct classification. The larger the difference between $p_{m}$ and $p_{m 2}$, the closer the value of
$C$ will be to either 1 (when the classification is correct) or to 0 (when the classification is incorrect). So the value of $C$ can be used as an indication of the "confidence" in the classification result.

\section{Results and discussion}

\section{Classical Analysis: POV and FFA}

The butter and butter oil samples were left untreated and were subjected to heat treatment 1 , heat treatment 2 , and/or the off-flavouring treatment. To evaluate the effects of the treatment on the oxidation of the butter and butter oil samples, POV and FFA concentrations were determined (Tables 1, 2, respectively). No significant differences in POV or FFA values were observed between the two matrices (butter versus butter oil; ANOVA, $P<0.05$ ). When comparing the treatments, the POV values of the untreated samples appeared significantly lower than their heat treated or off-flavoured counterparts (ANOVA, $P<0.0001)$. Peroxides are primary lipid oxidation products, and their concentrations are used as markers for lipid oxidation. The increased values after treatment of the milk fat samples show that some lipid oxidation occurred. For
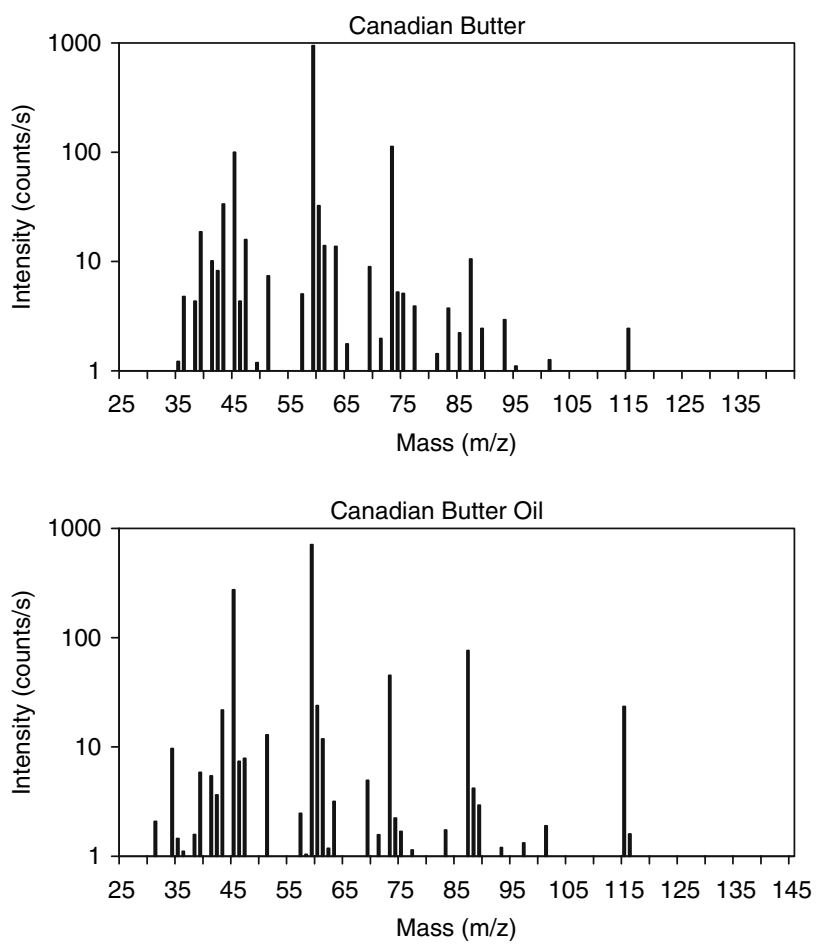

Fig. 1 Proton transfer reaction mass spectra of the headspace of Canadian butter and Canadian butter oil. Repeatability for individual ions was 21.1 and $24.2 \%$ for butter and butter oil samples, respectively 


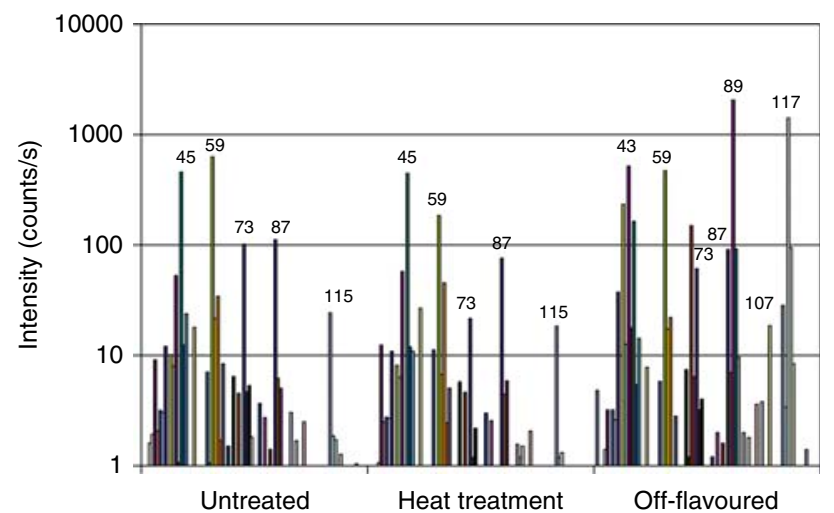

Fig. 2 Average proton transfer reaction mass spectra of the headspace of untreated, heat treated (average heat treatment 1 and 2) and off-flavoured milk fat samples

the FFA values, no significant differences between treatments were observed $(P<0.05)$.

\section{PTR-MS analysis}

The 37 milk fat samples were subjected to PTR-MS analysis. Two replicate analyses were carried out on each sample, and the resulting spectra were subsequently averaged. As an example, the mass spectra of Canadian butter and its butter oil counterpart are presented in Fig. 1. It is obvious from the mass spectrum that removal of water from butter has a considerable effect on the volatile profile of the sample.

The average mass spectra of untreated, heat-treated (average heat treatment $1+2$ ) and off-flavoured samples are shown in Fig. 2. In the untreated samples, the predominant ions were $\mathrm{m} / \mathrm{z} 59$ (631 counts/s), 45 (458 counts/ s), 87 (112 counts/s) and 73 (102 counts/s). They could originate from acetone/propanal ( $\mathrm{m} / \mathrm{z} 59)$, acetaldehyde $(\mathrm{m} / \mathrm{z} 45)$, diacetyl $(\mathrm{m} / \mathrm{z} 87)$ and various aldehydes and ketones $(\mathrm{m} / \mathrm{z} 73)[14,15]$. In order to compare the origins, a PCA was carried out on the mass spectral data of the untreated butter samples (plot not shown). The Irish butter was separated from the other butters on the first dimension, which explained $52 \%$ of the variance. This sample correlated with high intensities of a large range of masses. The other butters were separated on the second dimension (explaining $18 \%$ of the variance). The Dutch butters had high negative scores, which correlated with high intensities of the ions m/z 83, 95, 107, 109 and 137. Mass m/z 83 has been reported as major product ion of hexanal and mass $\mathrm{m} /$ z 95 from dimethyl disulfide [14]. Mass m/z 107 has been identified tentatively to originate from benzaldehyde and $o, p, m$-xylene and mass m/z 109 from trans-2-octenal in young Trentingana cheeses [16]. Mass $\mathrm{m} / \mathrm{z} 137$ has been reported as the parent ion of many monoterpenes, including limonene [17]. The butters from New Zealand, Canada and Portugal had high positive scores on the second dimension, which correlated with low ion intensities in general. The compounds listed are potential candidates only and related to volatile compounds, reported in the literature as being present in dairy products and which would produce a signal on the given mass. The differences between the origins are only indicative; analyses of more products per country would be required to classify the samples by their origin.

For the heat-treated samples, on average, the major ions were $\mathrm{m} / \mathrm{z} 45$ (445 counts/s), 59 (185 counts/s), 87 (76 counts/s) and 43 (58 counts/s). Three of the masses $(59,45$ and 87 ) occur in both situations, so the spectra of the untreated and heat-treated samples showed similarities in their predominant ions. The data of the untreated and heattreated samples were subjected to PCA and plots of the first two dimensions are presented separately for butter and butter oil in Fig. 3. The PCA shows that the untreated group is the most widely spread, especially for butter oils. The two heat treatments changed the spectra in the same direction, with the more severe heat treatment 2 resulting in more pronounced changes. Generally, the heat treatments resulted in higher negative scores in the second dimension.

For the off-flavoured samples, however, highest intensities were observed for the ions $\mathrm{m} / \mathrm{z} 89$ (2,064 counts/s),
Fig. 3 Sample scores of the first two dimensions of Principal Component Analysis on the mass spectral headspace data of treated and untreated butter (a) and butter oil (b): untreated samples (solid line), heat treatment 1 (dashed line), heat treatment 2 (dotted line)
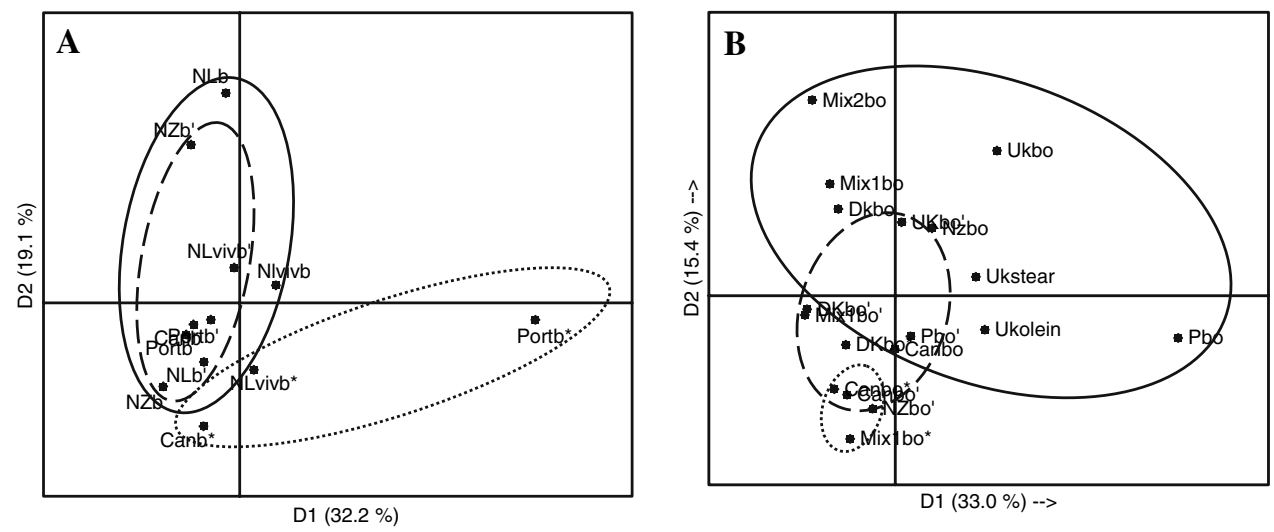
117 (1,414 counts/s), 43 (518 counts/s) and 59 (473 counts/ s). These results are in agreement with fragmentation studies carried out previously [15], which reported the major parent/fragment ions of ethyl butyrate: m/z 117, 89 and 43 . Incidentally, mass 43 was also found above with heat treatment 2. Mass $\mathrm{m} / \mathrm{z} 43$ is a fragment common to many compounds.

The volatile composition of butter and butter oil has been studied since the mid-1950s and an extensive list of volatiles has been compiled. As of 1996, 287 volatile compounds from 46 publications have been identified in butter and butter oil [18]. Various authors reported particular volatile compounds to contribute to the butter aroma, e.g. diacetyl, butanoic acid, hexanoic acid, hexanal, acetaldehyde, dimethyl sulphide and $\gamma$-decalactone [19], as well as $\delta$-octalactone, decanoic acid, phenol, $p$-cresol, indole and skatole [20]. Widder and Grosch [21] reported that in particular (Z)-2-nonenal and (E)-2-nonenal cause cardboard off-flavours in butter oil. However, most characterization studies have typically relied on relatively "rigorous" isolation procedures (vacuum distillation, solvent extractions, etc.) as opposed to headspace methods. Headspace analysis provides a more representative view of the volatiles that are available for olfactory perception. More recently, Peterson and Reineccius determined the volatile compounds, which are primarily responsible for the aroma of fresh and heated sweet cream butter [22, 23] using headspace analysis in combination with gas chromatography-olfactometry. A total of 20 odour active compounds were detected in the headspace of fresh butter and 19 in the headspace of heated butter. The major compounds in terms of concentration were certain lactones, hexanoic acid, butanoic acid, nonanal, hexanal and dimethyl sulphide for the fresh butter [22]. In the heated butter, higher concentrations were determined for lactones, 2-heptanone, butanoic acid, nonanal, (E)-2-nonenal and 3-methylbutanoic acid [23]. When comparing the predominant ions determined in the present study with the volatile compositions of butter and butter oil published, fragmentation patterns need to be considered as well [15]. Although some information on the volatile composition of the samples is available with PTR-MS analysis, the technique should be considered as a one-dimensional technique. Its strengths do not lie in identification of volatile compounds, but in rapid generation of fingerprints of volatile profiles.

\section{Sensory analysis}

Following the classical and PTR-MS analysis, the 37 samples were sensorially assessed and graded by dairy judges (Table 1,2). Six of the 15 butter samples and 4 of the 22 butter oils showed sensory defects. Some of the samples were untreated (e.g. the Irish butter and the goat butter) and others had been subjected to treatments. Surprisingly, the sensory analysis of butter has not been a subject of exhaustive study. The odour active compounds have been identified [19-23], and several studies on the sensory evaluation of butter with a focus on texture have been published [24]. Jinjarak et al. [25] evaluated the textural as well as odour/flavour characteristics of sweet cream, and cultured and whey butter. The flavour of sweet cream butter was characterized by the following flavour attributes: diacetyl, artificial butter, nutty, acidic, sweet, rancid, grassy and cardboard flavour. The effect of varying fatty acid compositions on the texture as well as milky taste and aftertaste has been published by Chen et al. [26].

The sensory quality of dairy products is governed by a number of factors linked to their production. The chemical and microbiological characteristics of the raw milk used also play a major role. The characteristics of raw milk used are dependent on factors linked to animal management. Many studies on the effect of animal feeding on dairy product sensory quality have been carried out over the last decade [27-29]. Differences in flavour of dairy products could result from differences in the fatty acid composition according to the diets consumed. The unsaturated fatty acids are more susceptible to oxidation. Kirstensen et al. [30] reported that buttermilk from milk rich in unsaturated fatty acids, obtained by manipulation of the cows' diet, was less oxidatively stable during storage than buttermilk from milk comprising higher

Table 3 Number and (percentages) of predicted classification of milk fat samples into butter and butter oil classes by their PTR-MSpectral data using a two-component PLS-DA model as well as the results of two permutation sets

\begin{tabular}{|c|c|c|c|c|c|c|c|}
\hline & \multicolumn{6}{|c|}{ PLS-DA classification } & \multirow[t]{3}{*}{ Number of samples } \\
\hline & \multicolumn{2}{|c|}{ Original data } & \multicolumn{2}{|c|}{ Permutation 1} & \multicolumn{2}{|c|}{ Permutation 2} & \\
\hline & Butter & $\overline{\text { Butter oil }}$ & Butter & $\overline{\text { Butter oil }}$ & Butter & $\overline{\text { Butter oil }}$ & \\
\hline Butter & $13(87 \%)$ & $2(13 \%)$ & $\mathbf{3}(\mathbf{2 0} \%)$ & $12(80 \%)$ & $11(73 \%)$ & $4(27 \%)$ & 15 \\
\hline Butter oil & $4(18 \%)$ & $18(82 \%)$ & $10(45 \%)$ & $12(55 \%)$ & $16(73 \%)$ & $6(27 \%)$ & 22 \\
\hline
\end{tabular}

The correctly classified samples are in bold. Out of 37 samples, 31 were correctly classified (84\%) 

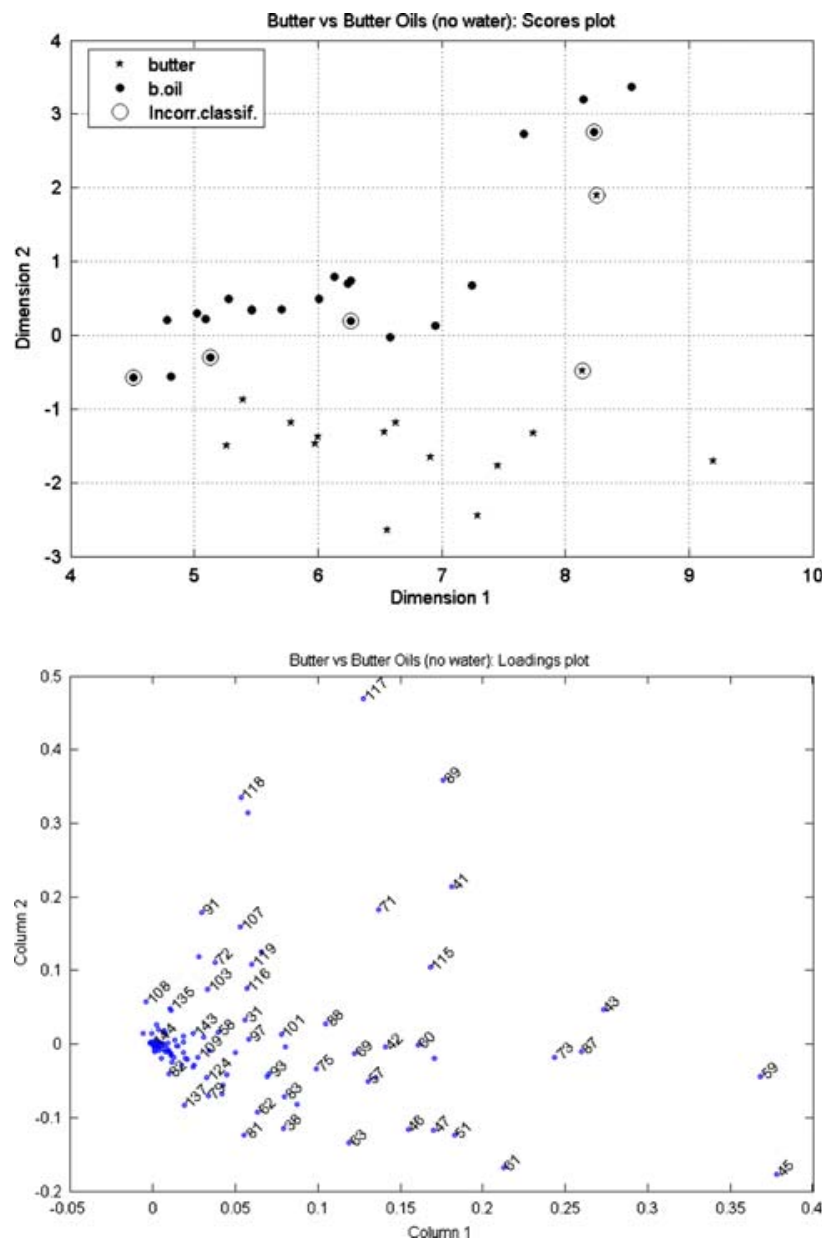

Fig. 4 Plot of the first two dimensions of PLS-DA on the mass spectral headspace data of butters and butter oils classified by matrix (butter/butter oil): scores (upper) and loadings plot (lower)

Table 4 Average number and (percentage) of incorrect classifications over 100 replications of the cross validation for the prediction into butter and butter oil classes by the PTR-MSpectral data, for the original data and for randomly permuted data sets

\begin{tabular}{|c|c|c|c|}
\hline & \multicolumn{2}{|c|}{ PLS-DA classification } & \multirow[t]{2}{*}{ Number of samples } \\
\hline & Original data & Random permutations & \\
\hline Butter & $2.06(14 \%)$ & $8.39(56 \%)$ & 15 \\
\hline Butter oil & $4.42(20 \%)$ & $9.96(45 \%)$ & 22 \\
\hline Total & $6.48(18 \%)$ & $18.35(50 \%)$ & \\
\hline
\end{tabular}

A two-component PLS-DA model was fitted for all classifications

levels of saturated fatty acids. It appears that in particular, unsaturated fatty acids may be degraded by microbial enzymes in the rumen and produce compounds responsible for dairy products aromas [31]. Apart from the characteristics of the milk, processing and storage considerably affect the sensory properties of butter and butter oil.

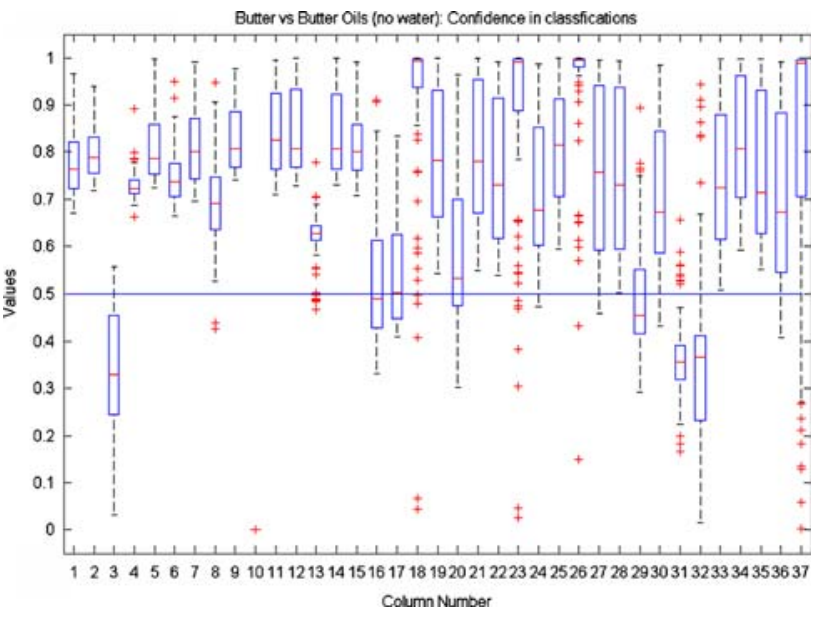

Fig. 5 Results for 100 replications of the random cross validation of the predicted classification of milk fat samples into butter and butter oil classes by their PTR-MSpectral data using a two-component PLSDA model. For each of the 37 samples, a box shows the location of the .25 and .75 quartiles of the quantity $C$ (see text), the dotted lines (whiskers) are the whiskers; they have a length of 1.5, * the interquartile range (or shorter, if there are no more observations), and the crosses are outliers, lying outside the whiskers. The data have been sorted so that columns 1-15 are for class 1 samples (butter), and columns 16-37 are for class 2 samples (butter oils)

\section{PLS-DA classification into matrix and sensory quality groups using PTR-MS data}

\section{Matrix}

PLS-DA was applied to the mass spectral data to classify the samples into matrix groups (butter or butter oil), using the mass spectra. A two-component model was fitted to estimate the matrix of the samples. Rates of successful classification are listed in the leftmost part of Table 3. Of all samples, $84 \%$ were successfully classified into butter and butter oil classes: 13 of the 15 butters (87\%) and 18 of the 22 butter oils (82\%). The scores of the samples on the first two PLS-dimensions are presented in Fig. 4 (top). The six incorrectly classified samples are identified by a circle. All of these incorrectly classified samples are more or less on the demarcation line between the two classes. The classes seem to be distinguished mainly by the second component. The variables (ions) can also be plotted in the component space (Fig. 4, bottom). Ions showing higher positive loadings in the second dimension, such as masses 117, 118 and 89, are associated with butter oils; those with lower positive or negative loadings on the second dimension are associated with butter. Considering the extremely wide range of sample material (origin, species, fractionation, deodorization, etc.), it is surprising that the samples could be so successfully classified. This may show the robustness of the PTR-MS technique in combination with PLS-DA. Ions, which are present in random concentrations 

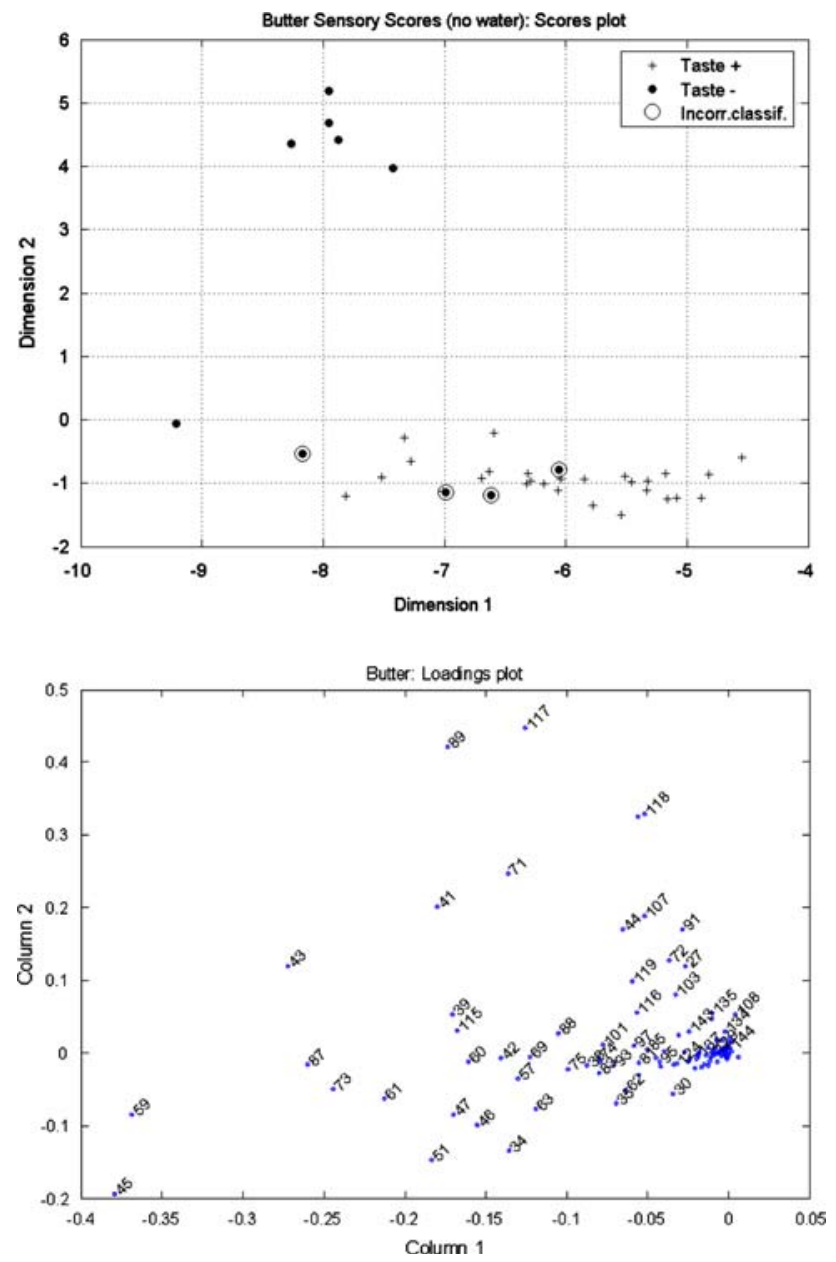

Fig. 6 Plot of the first two dimensions of PLS-DA on the mass spectral headspace data of butters and butter oils classified by their sensory qualities: scores (upper) and loadings plot (lower)

over butters and butter oils have only a marginal effect on the fitting of the model. On the other hand, those ions that can be used to discriminate butters from butter oils contribute considerably to the model estimation. The difference between the butters and butter oils lies mainly in their water content. Lower water content will generally result in lower air/product partition coefficients, as most volatile compounds are hydrophobic. On the other hand, the water is removed from the butter by heat treatments. During the heat treatment, some compounds may be formed. Furthermore, the butters also will have lost their original structure, which again may affect volatile release. The difference between butter and butter oils did not result in consistent differences in sensory quality as assessed by the sensory panel.

The two random permutations of the class labels resulted in far worse classification results, as can be seen in the middle and rightmost part of Table 3 . The overall percentage of correct classifications dropped from over 80 to around $50 \%$ (which is the percentage expected by chance alone) and even below. This indicates that the model does seem to fit in the systematic class differences and not merely noise. However, there is quite a large variation between the two permuted results (see also below). A total of 100 replications of the entire estimation process were performed, both for the original data and for permuted data, to gain insight into the stability of the cross validation results. For the original data, on average $13 \%$ of the butters are misclassified per replication, and $20 \%$ of the butter oils (see Table 4). With permuted data, these numbers were much higher: 56 and $45 \%$, respectively. Overall, there is $18 \%$ misclassification in the original data set, and $50 \%$ with permuted data.

A plot of the quantity $C$ is given in Fig. 5, for the original data only. This figure shows box plots of the distribution of the 100 values for $C$ obtained for each sample (for the definition of $C$, see the paragraph on "Statistical analysis"). For the ease of interpretation, the 15 butter samples are displayed first, then the 22 butter oils. It can be seen in the figure that the butters in columns 3 and 10 are nearly always (that is, in nearly each of the 100 replication of the cross validation) incorrectly classified. These are the heat-treated Portuguese butter, and the Dutch off-flavoured goat butter. For the goat butter, the confidence in the incorrect classification is always maximal, resulting in a box plot of width virtually 0 . The butter oils in columns 31 and 32 are also very often misclassified, as well as, to a lesser extent, the butter oil in column 29. All of these samples were heat-treated samples (heat treatment 1 or 2). The additional volatile compounds due to the

Table 5 Number and (percentages) of predicted classification of butters and butter oils with good and poor sensory properties by their PTRMSpectral data using a two component PLS-DA model as well as the results of two permutation sets

\begin{tabular}{|c|c|c|c|c|c|c|c|}
\hline & \multicolumn{6}{|c|}{ PLS-DA classification } & \multirow[t]{3}{*}{ Number of samples } \\
\hline & \multicolumn{2}{|c|}{ Original data } & \multicolumn{2}{|c|}{ Permutation 1} & \multicolumn{2}{|c|}{ Permutation 2} & \\
\hline & Good & Poor & Good & Poor & Good & Poor & \\
\hline Good & $27(100 \%)$ & $0(0 \%)$ & $24(89 \%)$ & $3(11 \%)$ & $7(26 \%)$ & $20(74 \%)$ & 27 \\
\hline Poor & $4(40 \%)$ & $6(60 \%)$ & $6(60 \%)$ & $4(40 \%)$ & $2(20 \%)$ & $8(80 \%)$ & 10 \\
\hline
\end{tabular}

The correctly classified samples are in bold. Out of 37 samples, 33 were correctly classified (89\%) 
Table 6 Average number and (percentage) of incorrect classifications over 100 replications of the cross validation for the prediction into good and poor sensory quality classes by the PTR-MSpectral data, for the original data and for randomly permuted data sets

\begin{tabular}{llll}
\hline & \multicolumn{2}{l}{ PLS-DA classification } & $\begin{array}{l}\text { Number of } \\
\text { samples }\end{array}$ \\
\cline { 2 - 3 } & Original data & Random permutations & \\
\hline Good quality & $0.59(2 \%)$ & $11.22(42 \%)$ & 27 \\
Poor quality & $3.99(40 \%)$ & $5.56(57 \%)$ & 10 \\
Total & $4.58(12 \%)$ & $16.78(46 \%)$ & \\
\hline
\end{tabular}

A two-component PLS-DA model was fitted for all classifications

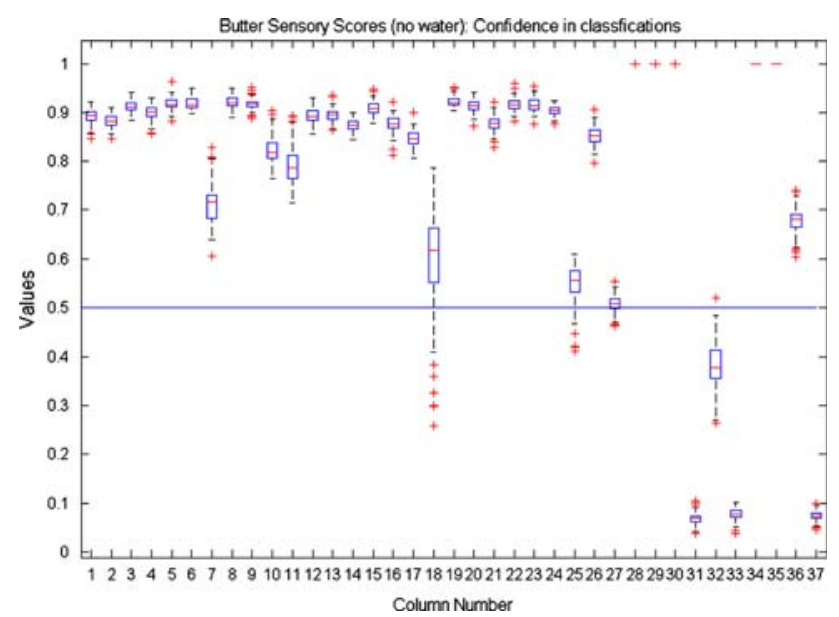

Fig. 7 Results for 100 replications of the random cross validation of the predicted classification of milk fat samples into good and poor sensory quality classes by their PTR-MSpectral data using a twocomponent PLS-DA model. For each of the 37 samples, a box shows the location of the .25 and .75 quartiles of the quantity $C$ (see text), the dotted lines (whiskers) are the whiskers; they have length 1.5, * the interquartile range (or shorter, if there are no more observations) and the crosses are outliers, lying outside the whiskers. The data have been sorted so that columns 1-27 are for class 1 samples (good quality), and columns $28-37$ are for class 2 samples (poor quality)

treatments resulted in mass spectral changes. Some of these changes may complicate the assignment to classes, resulting in lower confidence in the classification into the butter or butter oil class. The box plots for the permuted data (not printed here) are much more centred around the value 0.5 , indicating that both correct and incorrect classifications occur.

\section{Sensory quality}

The mass spectra generated by PTR-MS in the present study were used to fit a two-component PLS-DA model predicting the sensory grading (good or poor sensory quality) of the dairy experts. The sample scores on the first two dimensions are shown in the PLS-DA plot in Fig. 6.
Rates of correct classifications for good and poor sensory quality samples are listed in Table 5. In total, $89 \%$ of the samples were correctly classified, 27 out of the 27 good quality samples $(100 \%)$, and 6 out of the 10 poor quality samples (60\%). Poor quality samples scored relatively low on the first dimension and high on the second dimension, compared to the good quality samples. This time, the incorrect classifications are not on the demarcation line, but on the scores plot it can be seen that some of the poor quality samples are located right among the good quality samples.

In the two permutations presented (rightmost part of Table 5), the correct classification rate does not drop as dramatically as with the classification into butter and butter oil. The 100 replications of the analysis (Table 6), however, reveal that this is just a "bad luck" result: for permuted data, $46 \%$ is incorrectly classified, and for the original data it is only $12 \%$.

As could, perhaps, be expected from the scores plot (Fig. 7, top), there are three poor quality samples rather consistently predicted as good quality samples (samples 31 , 33 and 37) and, to some extent, also sample 32. The samples that were incorrectly classified were the Dutch butter (NL2) and the Portuguese butter, which were subjected to heat treatment 1 . The Dutch goat butter was also incorrectly classified. The latter was expected to be picked up. The misclassification may be due to the relatively small group of samples, which had a poor flavour not resulting from the off-flavour treatment. The relatively small (nonhomogeneous) group and the cross validation involved may have complicated the classification. A reasonable classification based on sensory quality was obtained, although it is desirable to reduce the number of false positive results. It should be kept in mind, however, that for this classification the results of the sensory panel were considered to be the $100 \%$ correct classification of the samples. Misclassifications may also be due to the sensory panel results. For sensory analysis, as with other types of analyses, 5\% error is acceptable. This means that we cannot exclude one or two errors in the 37 evaluations. This could also have contributed to the "misclassifications". Especially, the treated Portuguese butter did not show any abnormalities in terms of POV or FFA values.

\section{Conclusions}

PTR-MS spectral data of milk fat samples were successfully used for classification of milk fat samples into both their matrix groups and groups of sensory quality. PLS-DA was shown as a useful statistical tool in classification studies. PTR-MS seems to be a promising technique with potential applications in quality control and control of 
regulations. Additional work, including the assessment of a wider range of well-defined butters and butter oils, could further assist in the evaluation of milk fat and shed more light on potential applications of PTR-MS for control purposes.

Acknowledgments The authors wish to thank VIV Vreeland, Zelhem (The Netherlands) for the supply of milk fat samples. The authors also acknowledge COKZ in Leusden (The Netherlands) for the sensory evaluation.

\section{References}

1. Dean N, Murphy TB, Downey G (2006) Using unlabelled data to update classification rules with applications in food authenticity studies. Appl Stat 55:Part 1 1-14

2. Arvanitoyannis IS, Tzouros NE (2005) Implementation of quality control methods in conjunction with chemometrics toward authentication of dairy products. Crit Rev Food Sci Nutr 45:231249

3. Reid LM, O'Donnell CP, Downey G (2006) Recent technological advances for the determination of food authenticity. Trends Food Sci Technol 17:344-353

4. Pollien P, Lindinger C, Yeretzian C, Blank I (2003) Proton transfer reaction mass spectrometry, a tool for on-line monitoring of acrylamide formation in the headspace of Maillard reaction systems and processed food. Anal Chem 75(20):5488-5494

5. Biasioli F, Gasperi F, Aprea E, Colato L, Boscaini E, Märk TD (2003) Fingerprinting mass spectrometry by PTR-MS: heat treatment vs. pressure treatment of red orange juice, a case study. Int J Mass Spectrom 223-224:343-353

6. van Ruth SM, Dings L, Buhr K, Posthumus MA (2004) In vitro and in vivo volatile flavour analysis of red kidney beans by proton transfer reaction mass spectrometry. Food Res Int 37:785791

7. Biasioli F, Gasperi F, Odorizzi G, Aprea E, Mott D, Marini F, Autiero G, Rotondo G, Märk TD (2004) PTR-MS monitoring of odour emissions of composting plants. Int $\mathrm{J}$ Mass Spectrom 239:103-109

8. Biasioli F, Gasperi F, Aprea E, Mott D, Boscaini E, Mayr D, Märk TD (2003) Coupling proton transfer reaction mass spectrometry with linear discriminant analysis: a case study. J Agric Food Chem 51(25):7227-37233

9. Biasioli F, Gasperi F, Aprea E, Endrezzi I, Framondino V, Marini F, La Mott D, Märk TD (2006) Correlation of PTR-MS spectral fingerprints with sensory characterisation of flavour and odour profile of 'Trentingrana' cheese. Food Qual Pref 17(1-2):63-75

10. Aprea E, Biasioli F, Gasperi F, Märk TD, van Ruth S (2006) In vivo monitoring of strawberry flavour release from model custards: effect of texture and oral processing. Flav Fragr J 21:53-58

11. Lindinger W, Hirber J, Paretzke H (1993) An ion/moleculereaction mass spectrometer used for on-line trace gas analysis. J Mass Spectrom Ion Process 129:79-88

12. Hansel A, Jordan A, Holzinger R, Prazeller P, Vogel W, Lindinger W (1995) Proton transfer reaction mass spectrometry: online trace analysis at the ppb level. Int J Mass Spectrom Ion Process 149/150:609-619
13. Wise BM, Shaver JM, Gallagher NB, Windig W, Bro R, Koch RS (2006) PLS-Toolbox 4.0 for use with MATLAB ${ }^{\text {tm }}$. Eigenvector Research Inc., Wenatchee

14. Warneke C, de Gouw JA, Kuster WC, Doldan PD, Fall R (2003) Validation of atmospheric VOC measurements by proton transfer reaction mass spectrometry using a gas chromatographic preseparation method. Environ Sci Technol 37:2494-2501

15. Buhr K, van Ruth S, Delahunty C (2002) Analysis of volatile flavour compounds by proton transfer reaction-mass spectrometry: fragmentation patterns and discrimination between isobaric and isometric compounds. Int J Mass Spectrom 221:1-7

16. Aprea E, Biasioli F, Gasperi F, Mott D, Marini F, Maerk TD (2007) Assessment of Trentingrana cheese ageing by proton transfer reaction/mass spectrometry and chemometrics. Int Dairy J 17:226-234

17. Tani A, Hayward S, Hewitt CN (2003) Measurement of monoterpenes and related compounds by proton transfer reaction-mass spectrometry (PTR-MS). Int J Mass Spectrom 223-224:561-578

18. Maarse H, Visscher CA (1996) Volatile compounds in foods: qualitative and quantitative data. In: Boelens MH (ed). TNO, The Netherlands

19. Siek TJ, Lindsay RC (1968) Volatile components of milk fat steam distillates identified by gas chromatography and mass spectrometry. J Dairy Sci 51:1887-1896

20. Urbach G, Stark W, Forss AD (1972) Volatile compounds in butter oil. II. Flavor and flavor thresholds of lactones, fatty acids, phenols, indole and skatole in deodorized synthetic butter. J Dairy Res 39:35-47

21. Widder S, Grosch W (1994) Study on the cardboard off-flavour formed in butter oil. Z Lebensm Unters Forsch 198:297-301

22. Peterson DG, Reineccius GA (2003) Characterization of the volatile compounds that constitute fresh sweet cream butter aroma. Flav Fragr J 18:215-220

23. Peterson DG, Reineccius GA (2003) Determination of the aroma impact compounds in heated sweet cream butter. Flav Fragr J 18:320-324

24. Kleyn DH (1992) Textural aspects of butter. Food Technol 46:118-121

25. Jinjarak S, Olabi A, Jiménez-Flores R, Walker JH (2006) Sensory, functional, and analytical comparisons of whey butter with other butters. J Dairy Sci 89:2428-2440

26. Chen S, Bobe G, Zimmerman S, Hammond EG, Luhman CM, Boylston TD, Freeman AE, Beitz DC (2004) Physical and sensory properties of dairy products from cows with various milk fatty acid compositions. J Agric Food Chem 52:3422-3428

27. Coulon J-B, Delacroix-Buchet A, Martin B, Pirisi A (2004) Relationships between ruminant management and sensory characteristics of cheeses: a review. Lair 84:221-242

28. Martin B, Verdier-Metz I, Buchin S, Hurtaud C, Coulon J-B (2005) How do the nature of forages and pasture diversity influence the sensory quality of dairy livestock products? Anim Sci 81:205-212

29. Couvreur S, Hurtaud C, Lopez C, Delaby L, Peyraud JL (2006) The linear relationship between the propotion of fresh grass in the cow diet, milk fatty acid composition, and butter properties. J Dairy Sci 89:1956-1969

30. Kirstensen D, Hedegaard TV, Nielsen JH, Skibsted LH (2004) Oxidative stability of buttermilk as influenced by the fatty cid composition of cows'milk manipulated by diet. J Dairy Res 71:46-50

31. Urbach G (1990) Effect of feed on flavor in dairy foods. J Dairy Sci 73:3639-3650 